\title{
Nanosized Multifunctional Polyplexes for Receptor-Mediated SiRNA Delivery
}

\author{
Christian Dohmen, ${ }^{\dagger}$ Daniel Edinger, ${ }^{\dagger}$ Thomas Fröhlich, ${ }^{\dagger}$ Laura Schreiner, ${ }^{\dagger}$ Ulrich Lächelt, ${ }^{\dagger}$ Christina Troiber, ${ }^{\dagger}$ \\ Joachim Rädler, ${ }^{\ddagger}$ Philipp Hadwiger, ${ }^{\S}$ Hans-Peter Vornlocher, ${ }^{\S}$ and Ernst Wagner ${ }^{\dagger, *}$ \\ ${ }^{\dagger}$ Pharmaceutical Biotechnology, Center for NanoScience, Ludwig-Maximilians-University Munich, Butenandtstrasse 5-13, 81377 Munich, Germany, ${ }^{\ddagger}$ Department of \\ Physics, Center for NanoScience, Ludwig-Maximilians-University Munich, Amalienstraße 54, 80799, Munich, Germany, and ${ }^{\S}$ Axolabs GmbH, Fritz-Hornschuh-Straße 9 , \\ 95326 Kulmbach, Germany
}

R NAi-based therapy continues to be one of the most promising concepts for the treatment of several diseases, especially cancer. Although the biological process of gene silencing is understood in its details, thus enabling the design of very efficient and safe synthetic siRNA molecules, the main challenge in this field remains delivery. The nucleic acid has to overcome many hurdles when injected locally or intravenously. Crucial steps such as stability and protection in the extracellular environment, recognition of the target cell, overcoming the barrier of cellular membranes, and entrance into the cytosol remain challenging bottlenecks in the delivery process. ${ }^{1-5}$ As viral carriers are still subject to safety concerns, especially for systemic delivery, synthetic structures have been developed to overcome limitations in the delivery process. In addition to liposomes and lipoplexes, polycations represent an important group of molecules showing encouraging potential as carrier systems. ${ }^{6-11}$ Although classical cationic polymers such as polyethylenimine (PEI) have shown the ability to transport nucleic acids, they still lack efficiency compared to their viral counterparts. Thus functional substructures, addressing key limitations in the delivery process, have been incorporated into these polymers by chemical conjugation. For the reduction of interactions with blood compounds and an increased polyplex stability, poly(ethylene glycol) (PEG) was coupled to the polycations. ${ }^{10,12-16}$ PEG is known to increase solubility and to efficiently shield attached molecules. Targeting ligands for overexpressed cell surface receptors were incorporated for preferential transfection of the intended tissue. ${ }^{10,14,17}$ As a further crucial step during the delivery process, the endosomal escape ability of polymeric carriers has been improved by addition of lytic

ABSTRACT Although our understanding of RNAi and our knowledge on designing and synthesizing active and safe siRNAs significantly increased during the past decade, targeted delivery remains the major limitation in the development of siRNA therapeutics. On one hand,

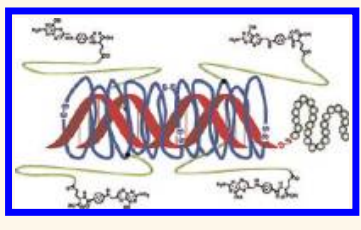
practical considerations dictate robust chemistry reproducibly providing precise carrier molecules. On the other hand, the multistep delivery process requires dynamic multifunctional carriers of substantial complexity. We present a monodisperse and multifunctional carrier system, synthesized by solid phase supported chemistry, for siRNA delivery in vitro and in vivo. The sequence-defined assembly includes a precise cationic (oligoethanamino)amide core, terminated at the ends by two cysteines for bioreversible polyplex stabilization, at a defined central position attached to a monodisperse polyethylene glycol chain coupled to a terminal folic acid as cell targeting ligand. Complexation with an endosomolytic influenza peptidesiRNA conjugate results in nanosized functional polyplexes of $6 \mathrm{~nm}$ hydrodynamic diameter. The necessity of each functional substructure of the carrier system for a specific and efficient gene silencing was confirmed. The nanosized polyplexes showed stability in vivo, receptorspecific cell targeting, and silencing of the EG5 gene in receptor-positive tumors. The nanosized appearance of these particles can be precisely controlled by the oligomer design (from 5.8 to $8.8 \mathrm{~nm}$ diameter). A complete surface charge shielding together with the high stability result in good tolerability in vivo and the absence of accumulation in nontargeted tissues such as liver, lung, or spleen. Due to their small size, siRNA polyplexes are efficiently cleared by the kidney.

KEYWORDS: RNAi polyplex folate targeting $\cdot$ endosomal escape lytic peptide

peptides. For example, acidic peptide analogues based on the amino terminus of the influenza virus hemagglutinin (HA-2) ${ }^{18,19}$ or masked mellitin derivatives ${ }^{16,20}$ were used, strongly boosting the activity of weakly effective polymers such as polylysine for pDNA and siRNA delivery. Furthermore, such conjugated polymers became bioresponsive, reacting to $\mathrm{pH}$ changes in the endosomal microenvironment. Despite great advances in the field, the high complexity of these new generations of polycationic polymers led to quite heterogenic, polydisperse
*Address correspondence to
Ernst.Wagner@cup.uni-muenchen.de.

Received for review March 3, 2012 and accepted May 30, 2012.

Published online May 30, 2012 10.1021/nn300960m

() 2012 American Chemical Society 


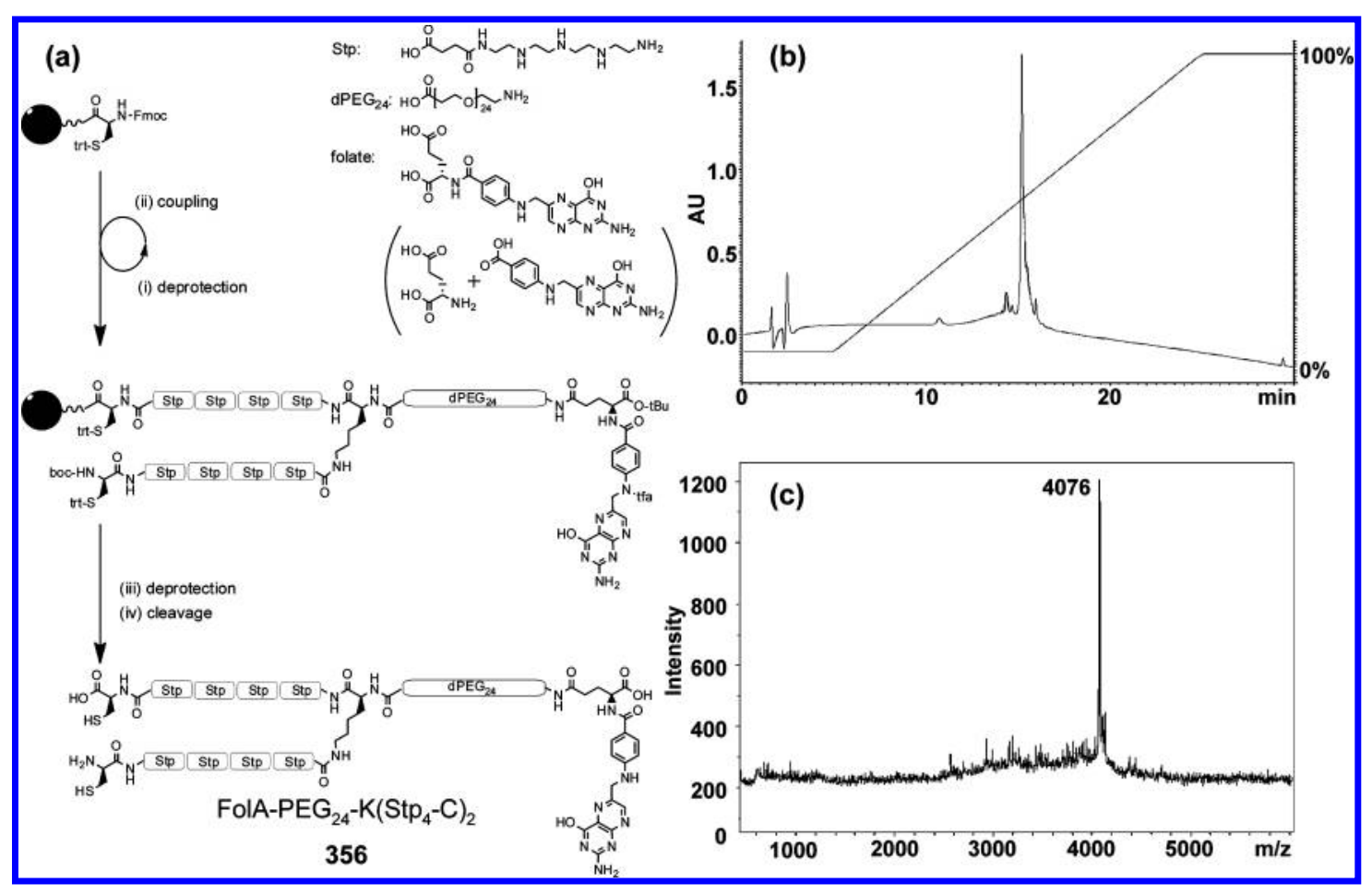

Figure 1. Synthesis and characterization of the folic acid targeted, defined polycation 356. (a) Scheme of synthesis on solid support. (b) Chromatogram of an analytical RP-HPLC run of the cleaved, deprotected, lyophilized polycation. (c) MALDI-TOFMS spectrum of the cleaved, deprotected, lyophilized polycation; calculated mass: $[\mathrm{M}+\mathrm{H}]^{+} 4076$.

structures. Reproducibility, purification, analytics, and a clear structure-activity relationship remain extremely difficult to achieve. As an additional complication, the formed polyplexes often are very polydisperse and large in size, presenting nanoparticle mixtures including polyplex aggregates. Small monomolecular complexes have been reported, ${ }^{21-24}$ however they often lack functional activity.

Recent studies generated libraries of molecularly defined polycationic structures, ${ }^{25-28}$ which reveal the benefit of precise carriers with clear structure-activity relationships. In the current work we extend this strategy by incorporating functional targeting, shielding, and endosomolytic domains into siRNA polyplexes in a highly defined fashion.

Persuing the concept described in Schaffert et al., ${ }^{27-29}$ we generated a nonpeptidic cationic backbone composed of (oligoethanamino)amide structures by solid phase supported (SPS) synthesis. SPS is continued by attachment of a monodisperse poly(ethylene glycol) chain at a defined position followed by regioselective coupling of folic acid as ligand for specific cell targeting. To increase the endosomal escape ability of the delivery system, Inf7 as an endosomolytic peptide was coupled to the $5^{\prime}$-end of the siRNA sense strand. Thus, in contrast to conventional polymer conjugate syntheses, the current design enables the synthesis of a molecularly precise product with beneficial delivery properties. We show the efficient synthesis and purification of these molecules, including a qualitative and quantitative analysis of the products. Functionality and necessity of every single substructure could be demonstrated separately, showing synergism on the siRNA silencing effect in vitro. Importantly, PEG-shielded unimolecular siRNA nanoparticles with a hydrodynamic diameter of only $5.8 \mathrm{~nm}$ and a neutral zeta potential were formed. Treatment of mice bearing subcutaneous tumors expressing the folic acid receptor showed that the targeted nanosized particles have an increased retention in the tumor tissue, resulting in a clear silencing effect without cross reactivity to other tissues.

\section{RESULTS AND DISCUSSION}

Design and Synthesis of the Defined Folic Acid Targeted Polycation. As a model system for our modular assembly strategy, we chose a structure for complexing siRNA, composed of eight artificial succinoyl tetraethylene pentamine (Stp) building blocks (Figure 1a) as a polycationic backbone containing 40 nitrogens, of which 24 are protonatable. The remaining 16 nitrogens are engaged in amide bond formation. In order to increase siRNA polyplex stability, cysteines were incorporated at the $\mathrm{C}$ - and $\mathrm{N}$-terminus of the peptide-like polycation, enabling the formation of disulfide bonds during polyplex formation. A monodisperse, commercially available heterobifunctional polyethylene glycol chain (Fmoc-N-amido-dPEG24-acid, QuantaBiodesign, $\mathrm{OH}, \mathrm{USA}$ ) was introduced into the oligomer chain at a defined position using lysine as a branching point 


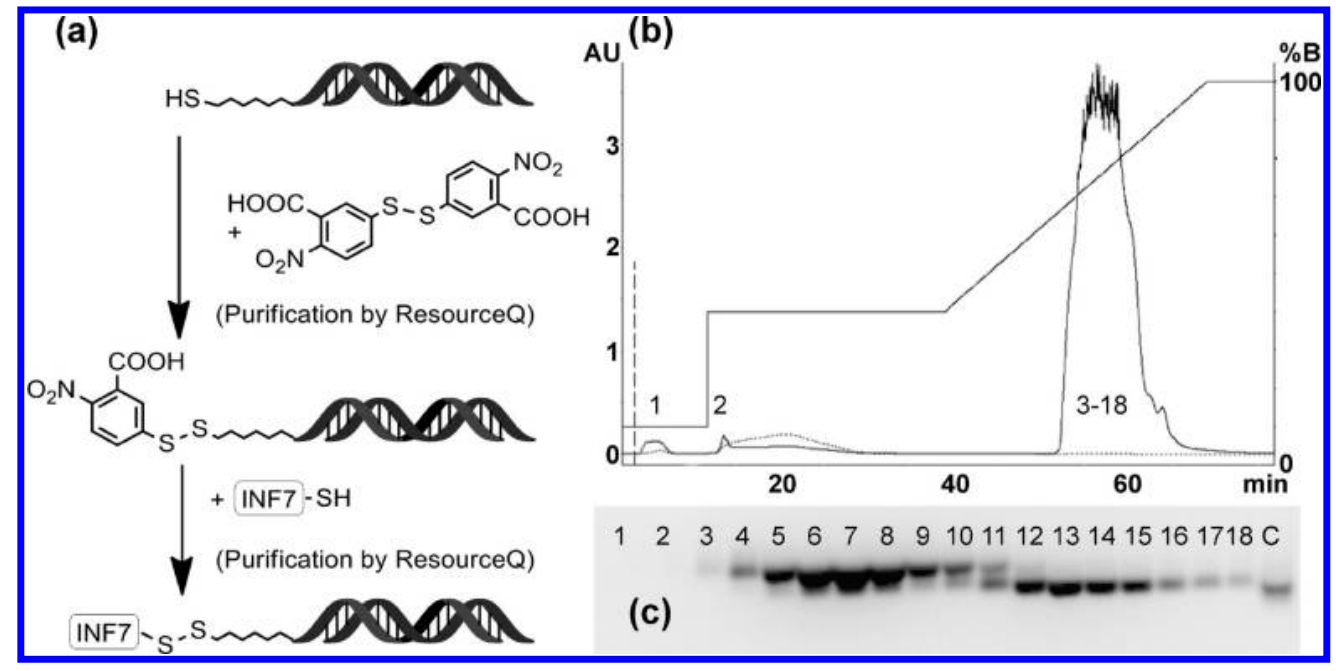

Figure 2. Synthesis and characterization of the influenza peptide-siRNA conjugate. (a) Synthesis scheme. The resulting conjugate was purified via strong anion exchange chromatography. (b) Chromatogram of the siRNA-Inf7 conjugate purification using a ResourceQ column (1 mL, GE Healthcare) connected to an Äkta basic system, detection at $260 \mathrm{~nm}$. 1-18: Collected fractions for analysis. (c) Analytical agarose gel electrophoresis of HPLC fractions. The $0.5 \mathrm{~mL}$ fractions were collected during conjugate purification. Fractions 5-8 containing siRNA with altered electrophoretic mobility compared to unmodified siRNA (C) were collected and analyzed by MALDI-TOF-MS.

(Figure 1a). The PEG chain was extended by coupling of glutamic acid followed by pteroic acid, resulting in a folate ligand as targeting structure. As it is known that the coupling of folic acid via its $\alpha$-carboxy group results in a reduced binding affinity to its receptor, the coupling was performed via its $\gamma$-carboxy group. ${ }^{30}$ Purity and identity of the synthesized structure FolA-PEG ${ }_{24}$ $\mathrm{K}\left(\mathrm{Stp}_{4}-\mathrm{C}\right)_{2}$ (356) was demonstrated by analytical RP-HPLC (Figure 1b), MALDI-TOF-MS analysis (Figure 1c), and ${ }^{1} \mathrm{H}$ NMR (Figure S1a). Controls lacking the targeting ligand (188) or its cysteines (420) were synthesized persuing analogous procedures (for analysis see Figures $\mathrm{S} 1 \mathrm{~b}$ and $\mathrm{S} 2$ ). Functional analogues with precise, longer PEG spacers, FolA-PEG ${ }_{48}-\mathrm{K}\left(\mathrm{Stp}_{4}-\mathrm{C}\right)_{2}$ (482) and FolA-PEG ${ }_{72}-\mathrm{K}\left(\mathrm{Stp}_{4}-\mathrm{C}\right)_{2}(\mathbf{4 8 3})$, are described in the Supporting Information (Figure S14).

Design and Synthesis of the Endosomolytic Active siRNAInfluenza Peptide Conjugate. As the targeted polycationic peptide includes functional substructures for siRNA binding, polyplex stability, and folate receptor targeting, endosomal escape is the remaining critical bottleneck. Most reported concepts used lytic peptides covalently attached to the polymeric carrier, ${ }^{16,19}$ which bears some risk of dissociation from the siRNA before cellular uptake. In this study the lytic peptide was coupled to the siRNA's backbone to ensure endosomal co-localization. Inf7, an acidic peptide analogue of the amino terminus of the influenza virus hemagglutinin, was chosen due to its overall negative charge and reported $\mathrm{pH}$-dependent lytic activity. ${ }^{18}$ The peptide was covalently conjugated to the $5^{\prime}$-end of the siRNA's sense strand to maintain the silencing efficiency. As shown in Figure 2a, the conjugate was prepared by activation of the siRNA's thiol group and subsequent reaction of the peptide's C-terminal cysteine. After purification of the conjugate by strong anion exchange chromatography (Figure 2b) the product was analyzed by agarose gel electrophoresis (Figure 2c). Fractions containing retarded siRNA compared to unconjugated input siRNA (fractions 5-8) were pooled and analyzed by MALDI-TOF-MS (Figure S3).

Functionality and Necessity of Substructures. Concepts including different substructures using common synthesis strategies are often limited in showing the beneficial effect of the incorporated substructures, due to very complex synthesis protocols. In this study we developed a system enabling a clear structureactivity relationship, minimizing the carrier to highly functionalized, necessary components for successful siRNA delivery. For siRNA binding the polycationic backbone consisting of eight Stp units was designed. Schaffert et al. already showed that Stp-bearing structures bind nucleic acids very efficiently when crosslinked via disulfide bonds. ${ }^{27}$ Thus cysteines were incorporated to enhance polyplex stability. The stabilizing effect is shown in a gel shift assay (Figure 3a), comparing the functional oligomer $\mathbf{3 5 6}$ with the analogue 420, bearing serines instead of cysteines. Data clearly show that an oligomer protonatable nitrogen/ siRNA phosphate (N/P) ratio of 6 leads to efficient siRNA binding, hampering its migration in the agarose gel in case of cysteine-bearing oligomer 356 . Without cross-linking ability (420), the binding is weaker and the payload is released from the carrier. This reveals that the combination of the polycationic backbone and cysteines results in efficient siRNA binding. A detailed analysis of polycation to siRNA binding revealed that an N/P ratio of 3 is sufficient for siRNA retardation (Figure S4), which is in good agreement with titration experiments of free oligomer, giving a protonation 


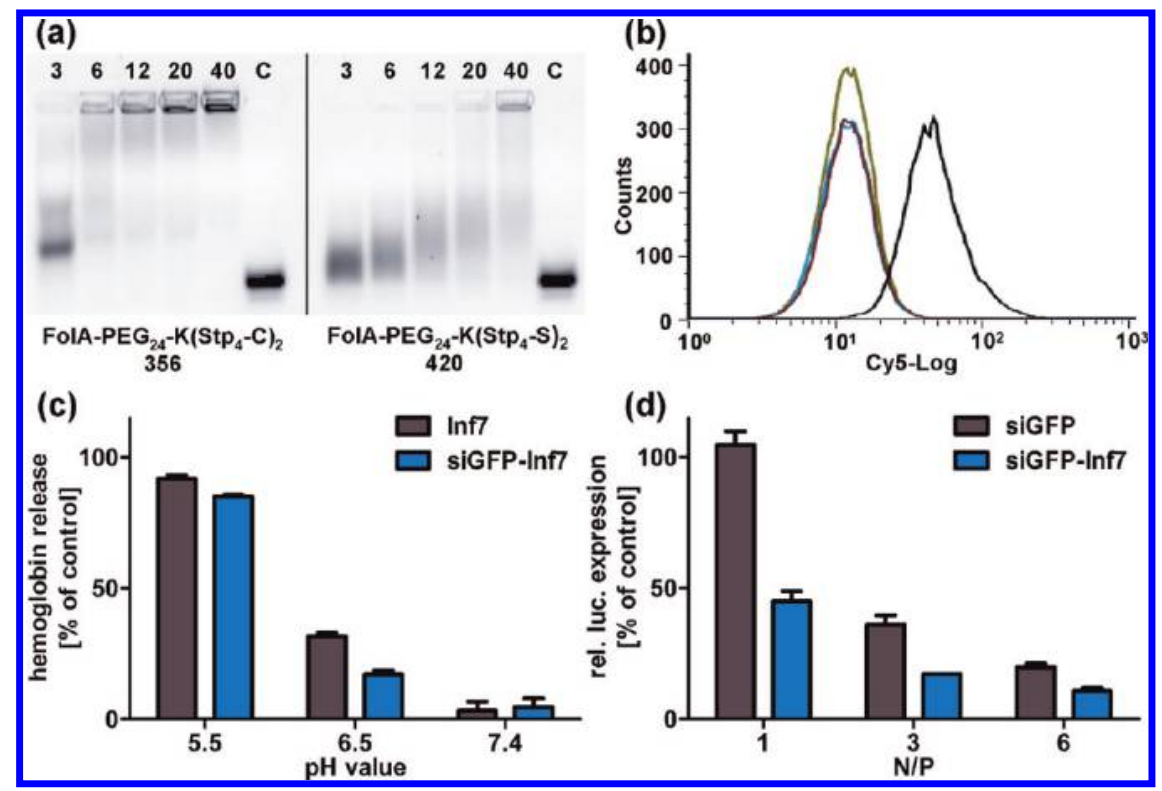

Figure 3. Functionality and necessity of carrier substructures. (a) Stabilization via disulfide cross-linking by gel shift assay at indicated N/P ratios. C: free siRNA-Inf7 control. (b) Shielding and targeting. KB cells were transfected using Cy5-labeled siRNAInf7 in combination with targeted, PEGylated oligomer 356 containing cysteines (black), untargeted PEGylated oligomer 188 containing cysteines (blue), or targeted PEGylated oligomer 420 lacking cysteines (red). After 30 min cells were washed, analyzed by FACS, and compared to nontransfected cells (green). (c) Functionality of modified Inf7 peptide. Lysis activity of $5 \mu \mathrm{M}$ siRNA-Inf7 (blue bars) was compared to the lysis activity of $5 \mu \mathrm{M}$ free Inf7 peptide (purple bars) in an erythrocyte leakage assay. (d) Functionality of modified siRNA. Neuro2A/eGFPLuc cells transfected with $400 \mathrm{nM}$ siRNA-Inf7 (blue bars) or $400 \mathrm{nM}$ unmodified siRNA (purple bars) using the functional, polycationic carrier 46 at indicated N/P ratios. Luciferase activity was determined after $48 \mathrm{~h}$ without medium exchange. Reporter gene knockdown is shown as percentage of untreated cells.

state of protonatable amines of $47 \%$ at pH 7.4 (Figure S5). Thus particles are formed until charge neutralization. Additional oligomer that was added after particle saturation stays free in solution, as demonstrated by a separate gel shift assay using Alexa488-labeled oligomer $\mathbf{5 8 3}$ in combination with siRNA-Inf7 (Figure S6). Disulfide exchange reactions between the siRNA-Inf7 disulfides and the added thiols of the polycation during polyplex formation would be a theoretical but unlikely possibility; as can be seen in Figure S7, disulfide exchange did not take place upon incubation of siRNA-Inf7 with free cysteine at the same doses as in polyplex formations. To shield the positive charge of the formed particles, a monodisperse $\mathrm{PEG}_{24}$ was incorporated into the carrier structure at a defined position. The efficient shielding blocks siRNA nanoparticle aggregation and led to nanoparticles with a hydrodynamic diameter of $5.8 \mathrm{~nm}$, only 1.4-fold larger than free siRNA with $4.2 \mathrm{~nm}$ hydrodynamic diameter (Table 1). The particle size does not increase with higher N/P ratios beyond 6, further supporting the notion that polyplex formation is a saturable process. This was further confirmed by fluorescence correlation spectroscopy measurements of Alexa488-labeled oligomer and siRNA-Inf7 polyplexes (Table S1). Free oligomer had a hydrodynamic diameter of $2.3 \mathrm{~nm}$. A two-component fit of polyplexes formed at N/P 6 resulted in two labeled populations, one with a hydrodynamic radius of $\sim 2 \mathrm{~nm}$ (free oligomer, $63 \%$ ) and a second with a hydrodynamic diameter of $\sim 7.4 \mathrm{~nm}$
TABLE 1. Hydrodynamic Diameter $\left(d_{h}\right)$ of Polyplexes Formed Using Cy5-Labeled siRNA-Inf7 in Combination with FolA-PEG ${ }_{24}-\mathrm{K}\left(\mathrm{Stp}_{4}-\mathrm{C}\right)_{2}$ Determined by Fluorescence Correlation Spectroscopy ${ }^{a}$

\begin{tabular}{lcc}
\multicolumn{1}{c}{$\mathbf{N} / \mathbf{P}$} & $\boldsymbol{d}_{\mathrm{h}}[\mathrm{nm}]$ & $\boldsymbol{D}\left[\mathbf{m}^{2} / \mathrm{s}\right]$ \\
\hline 0 (siRNA) & $4.2( \pm 0.2)$ & $10.0 \times 10^{-11}\left( \pm 3 \times 10^{-12}\right)$ \\
3 & $5.4( \pm 0.2)$ & $8.2 \times 10^{-11}\left( \pm 2 \times 10^{-12}\right)$ \\
6 & $5.8( \pm 0.2)$ & $7.7 \times 10^{-11}\left( \pm 2 \times 10^{-12}\right)$ \\
12 & $6.0( \pm 0.2)$ & $7.7 \times 10^{-11}\left( \pm 2 \times 10^{-12}\right)$ \\
16 & $6.0( \pm 0.2)$ & $7.7 \times 10^{-11}\left( \pm 2 \times 10^{-12}\right)$ \\
20 & $5.6( \pm 0.2)$ & $7.9 \times 10^{-11}\left( \pm 2 \times 10^{-12}\right)$ \\
40 & $5.6( \pm 0.2)$ & $8.1 \times 10^{-11}\left( \pm 2 \times 10^{-12}\right)$ \\
\hline
\end{tabular}

${ }^{a} D$ : diffusion coefficient. A single Cy5 label conjugated with the siRNA would not be expected to strongly change the polyplex properties because of its shielding within the PEG-oligomer coat.

(polyplexes, 37\%). Thus, one-third of the polycation is bound in polyplexes (actual N/P $\approx 2$ ) and two-thirds remain free in solution. This is well consistent with the literature. ${ }^{31}$ Upon increasing the PEG spacer to a 3-fold length (oligomer 483, FolA-PEG ${ }_{72}-\mathrm{K}\left(\mathrm{Stp}_{4}-\mathrm{C}\right)_{2}$; see Figure S14, Table S3), the nanoparticle size increases to $8.8 \mathrm{~nm}$ hydrodynamic diameter. This is consistent with the 3-fold PEG polymer length (diameter increases about $1.5 \mathrm{~nm}$ per $\mathrm{PEG}_{24}$ unit).

The PEGylated siRNA nanoparticles have an overall zeta potential of $0 \mathrm{mV}( \pm 3 \mathrm{mV}$ ) (see Table S2). Particles formed with the same oligomer lacking the polyethylene glycol structure (202) form much larger, 60-900 nm, nanoparticles and aggregates (see Table S4) and show 


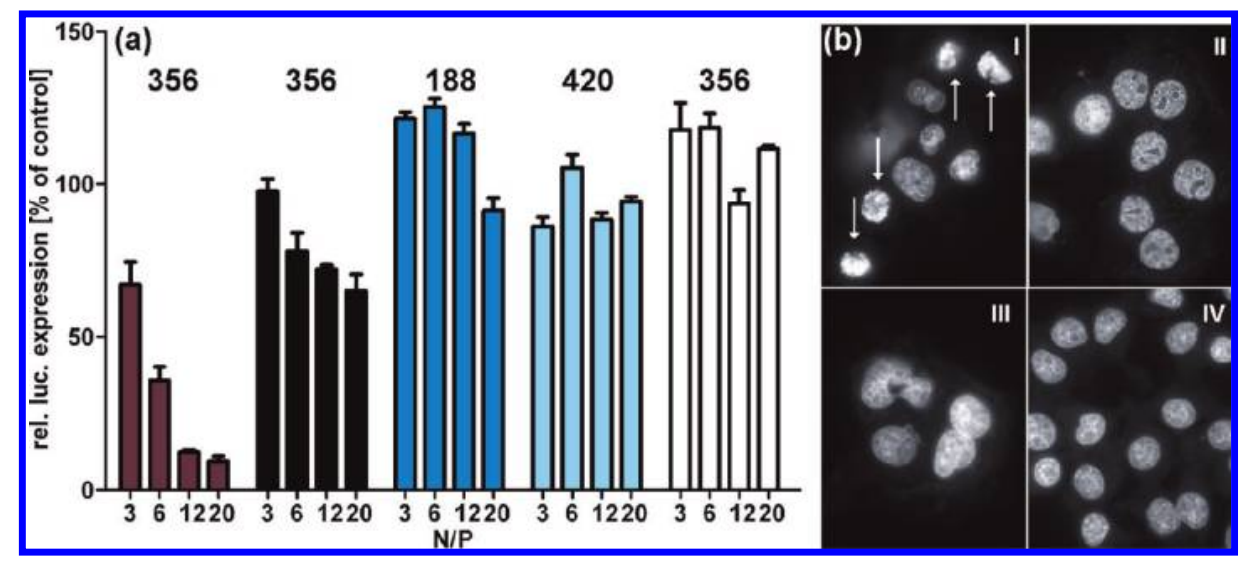

Figure 4. In vitro gene silencing using FolA-PEG ${ }_{24}-\mathrm{K}\left(\mathrm{Stp}_{4}-\mathrm{C}\right)_{2}$ (356) and siRNA-Inf7. (a) Luciferase reporter gene knockdown. $\mathrm{KB} / \mathrm{eGFPLuc}$ cells were transfected using the functional carrier (356) in combination with siGFP-Inf7 (purple bars) or with unmodified siGFP (black bars) at indicated N/P ratios. Control transfections were performed using carriers lacking either the targeting ligand (188, dark blue bars) or the cross-linking ability (420, light blue bars). To show specificity of knockdown, cells were transfected using the functional oligomer in combination with siCtrl-Inf7 (white bars). (b) Microscopic pictures of in vitro knockdown experiments using EG5 as endogenic target. KB cells were transfected using siEG5-Inf7 in combination with FolA$\mathrm{PEG}_{24}-\mathrm{K}\left(\mathrm{Stp}_{4}-\mathrm{C}\right)_{2}(356, \mathrm{I})$ or A-PEG $24-\mathrm{K}\left(\mathrm{Stp}_{4}-\mathrm{C}\right)_{2}\left(188\right.$, III), or siCtrl-Inf7 in combination with FolA-PEG ${ }_{24}-\mathrm{K}\left(\mathrm{Stp}_{4}-\mathrm{C}\right)_{2}(356$, II) or $A-\mathrm{PEG}_{24}-\mathrm{K}\left(\mathrm{Stp}_{4}-\mathrm{C}\right)_{2}(188, \mathrm{IV})$. Arrows: mitotic aster structures. Magnification: $630 \times$.

a significantly higher zeta potential, between 10 and $15 \mathrm{mV}$ (Table S2). Uncharged particles cannot attach to the cell surface via electrostatic interactions. Thus they would not interact randomly with cell surfaces and blood proteins ${ }^{32,33}$ when injected intravenously; however, they are not able to actively enter their target cells either. To enable an efficient receptor-mediated cellular uptake of the polyplex, folic acid was covalently attached to the PEG shield. As this ligand has a very high binding affinity to its receptor, ${ }^{34,35}$ it should selectively mediate cell attachment and endocytosis into its target cell. To demonstrate this, polyplexes were formed with siRNA-Inf7 bearing a fluorescent Cy5 label. After transfection of KB cells, expressing the folic acid receptor or Neuro2A cells as negative control, cellular uptake was analyzed quantitatively by flow cytometry measurement (Figures $3 \mathrm{~b}$ and 58 ). The results reveal that the particle shielding is very efficient. No fluorescent signal was detected in cells when carriers lacking the targeting ligand were employed. When transfected with folate-targeted particles, cells show a significantly increased uptake by flow cytometric analysis when receptor-positive $K B$ cells were used. In the case of Neuro2A cells, with a low folic acid receptor level, very moderate uptake could be observed. Competition with an excess of free folic acid leads to a strongly reduced cellular association (Figure S8). These results could be confirmed by microscopic analysis (Figure S9).

The second component of the delivery system is the endosomolytic-active siRNA-Inf7 conjugate. To demonstrate its functionality, the lytic activity was tested in comparison to free, unconjugated Inf7 peptide using an erythrocyte leakage assay. As shown in Figure $3 c$ the free peptide has no lytic activity at physiological $\mathrm{pH}$ ( $\mathrm{pH}$ of the extracellular environment and the cytosol), while the lytic activity is significantly increased at $\mathrm{pH}$ 5.5, mimicking the endosomal environment (as previously reported ${ }^{18}$ ). The lytic activity of the siRNAconjugated peptide shows no significant differences compared to the free peptide, revealing that it remains fully functional upon conjugation to the C-terminus. The preserved silencing activity of the conjugated siRNA was first shown in comparison to unmodified siRNA in a standard setting, transfecting Neuro2A/ eGFPLuc cells (Figure $3 d$ and Figure S10) using the defined but untargeted polycationic carrier $46 .{ }^{27}$ Results reveal that the silencing efficiency as well as cytotoxicity is not negatively affected by the attachment of the endosomolytic peptide via a disulfide linkage.

Efficient and Specific Reporter Gene Silencing in Vitro. Although all single substructures were shown to work as expected, the delivery system in total had to prove its transfection potency and gene silencing efficiency together with specificity to the target cell population and the absence of cytotoxicity. For this purpose KB cells (expressing the folate receptor) stably expressing an eGFP-luciferase fusion protein were used as reporter system. To demonstrate the importance of every single component of the system, controls lacking the folic acid ligand (188), the cysteine cross-linking ability (420), or the endosomolytic peptide were used. A nontargeting siRNA (siCtrl) was transfected to demonstrate specificity of target silencing. The results (Figure 4a, right lanes) clearly show that all controls lack silencing efficiency under the transfection conditions employed. The only control showing a significant but weak knockdown is the combination of unconjugated siRNA and functional carrier (356) at high N/P ratios. We conclude that the protone sponge effect of the polyamino backbone exists, but in the context of the very small PEGylated polyplexes on its own is not 


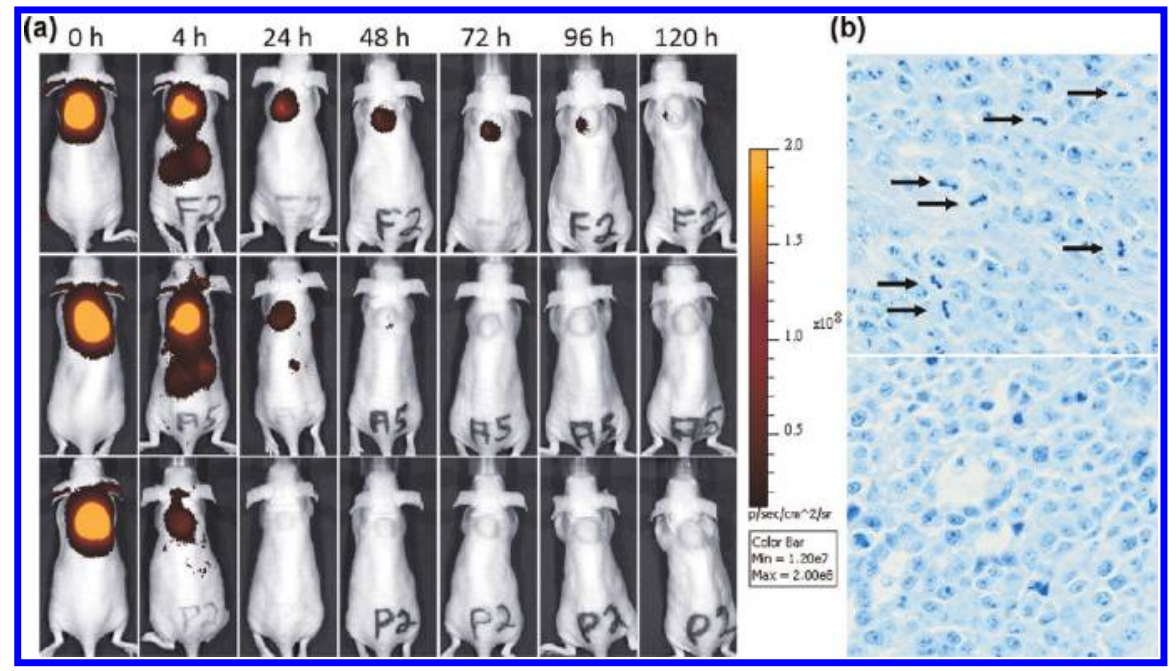

Figure 5. Intratumoral injection of siRNA polyplexes. (a) Retention of targeted polyplexes at the tumor site determined by NIR fluorescence bioimaging. FolA-targeted polyplexes (356, top), untargeted polyplexes (188, center), and equal amounts $(25 \mu \mathrm{g})$ of free Cy7-labeled siRNA (bottom). (b) Mitotic figure formation $24 \mathrm{~h}$ after intratumoral injection of targeted polyplexes in combination with siEG5-Inf7 (top) or siCtrl-Inf7 (bottom). Arrows label mitotic figures.

strong enough for endosomal escape. In contrast, a clear and significant silencing of the target gene (Figure 4a, left lanes) was obtained by combination of the functional carrier system with the endosomolytic siRNA-Inf7 conjugate, demonstrating the efficiency of the delivery system. An in vitro dose-response curve (Figure S11) comparing targeted (356) and nontargeted (188) polyplexes demonstrated a ligand-, Inf7-, and eGFP-sequence-dependent gene silencing at siRNA doses as low as $<6 \mathrm{nM}$. A direct comparison with the commercially available transfection agent Lipofectamine under recommended conditions (serumfree, $4 \mathrm{~h}$ incubation) revealed for carrier $\mathbf{3 5 6}$ at short incubation (only $30 \mathrm{~min}$, standard cell culture conditions) a high gene silencing efficiency at reduced toxicity (Figure S12). The replacement of the biodegradable disulfide linkage between siRNA and Inf7 by a noncleavable thioether bond resulted in a far lower silencing activity (Figure S13). To further characterize the gene silencing activity, an endogenous target was selected. The gene EG5 (also known as KSP) plays a crucial role during the cell cycle. The silencing of this gene has been shown to result in mitotic cell arrest and characteristic mitotic figure formation ("mitotic aster"). ${ }^{36}$ Thus KB cells were transfected with siEG5-Inf7, complexed with functional carrier or control oligomers. After staining, the microscopic pictures show the characteristic aster formation of the mitotic chromatin, indicating the specific knockdown of the target gene (Figure 4b, I). None of the control formulations led to this aster formation (Figure 4b, II-IV).

Tumor Target Gene Silencing in Vivo. The designed system has shown to work as expected in vitro. Thus the carrier was tested further in an in vivo setting. For this purpose polyplexes were prepared at N/P 16, based on the best in vitro transfection results due to the synergistic effect of endosomal buffering and swelling agent (oligoethanamino core) and endosomolytic influenza peptide. In the first experiments, polyplexes were injected intratumoraly, into subcutaneous tumors of NMRI nude mice, to determine whether the carrier is functional after reaching the tumor tissue. Near infrared (NIR) fluorescence imaging experiments using Cy7-labeled siRNA (Figures 5a and S18) proved that the incorporation of folic acid as targeting ligand results in a significantly increased retention in the tumor tissue compared to nontargeted particles. When injecting free siRNA, almost no retention and a fast clearance can be observed. Although a clear tumortargeting effect could be shown within this imaging experiment, the intracellular delivery of the siRNA and thus the functionality of the carrier had to be evaluated in a target gene silencing experiment. For this purpose EG5-Inf7 siRNA was injected intratumoraly, using FolA$\mathrm{PEG}_{24}-\mathrm{K}\left(\mathrm{Stp}_{4}-\mathrm{C}\right)_{2}$ (356) as carrier. In stained tumor slices of tumors harvested $24 \mathrm{~h}$ after treatment the formation of asters could be detected (Figure $5 b$ ). In contrast, no mitotic figures were observed in the case of siCtrl-Inf7-treated tumors.

As the intratumoral delivery was shown to work efficiently, proving folic acid targeting and gene silencing, the behavior of these nanosized particles after systemic application was evaluated. Interestingly, NIR fluorescence imaging revealed a short circulation time of $15 \mathrm{~min}$ followed by fast clearance through renal filtration, which can be explained by the small particle size (Figure 6a). Renal clearance was not influenced by the presence/absence of the folate targeting ligand (data not shown). Importantly, due to the excellent shielding of the polyplexes, unspecific affinity to tissues such as lung, liver, or spleen often observed with nanoparticles was not detectable (Figure 6b). Carriers 


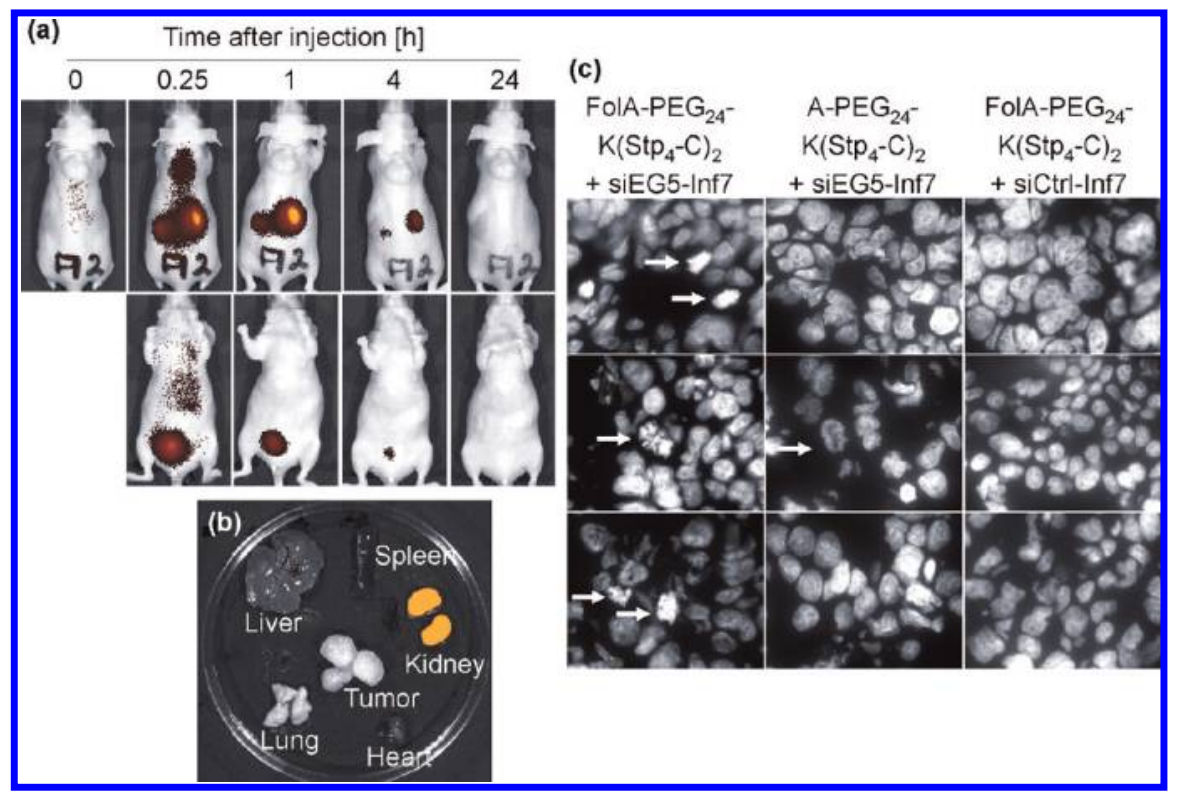

Figure 6. Intravenous administration of siRNA polyplexes. (a) Time-dependent distribution of $50 \mu \mathrm{g}$ Cy7-labeled siRNA after intravenous injection using FolA-PEG ${ }_{24}-\mathrm{K}\left(\mathrm{Stp}_{4}-\mathrm{C}\right)_{2}(356)$ as carrier. Upper panel: ventral position. Lower panel: dorsal position. (b) Organs at $1 \mathrm{~h}$ after injection. (c) Histochemical analysis of gene silencing (three tumor sections) by detection of aster formation. Mice were treated intravenously with FolA-PEG ${ }_{24}-\mathrm{K}\left(\mathrm{Stp}_{4}-\mathrm{C}\right)_{2}(356)$ or $\mathrm{A}-\mathrm{PEG}_{24}-\mathrm{K}\left(\mathrm{Stp}_{4}-\mathrm{C}\right)_{2}(188)$ in combination with siEG5-Inf7 or control siCtrl-Inf7.

with longer precise PEG spacers, FolA-PEG ${ }_{48}-\mathrm{K}\left(\mathrm{Stp}_{4}-\mathrm{C}\right)_{2}$ (482) and FolA-PEG ${ }_{72}-K\left(\mathrm{Stp}_{4}-\mathrm{C}\right)_{2}$ (483), increase the size of formed siRNA nanoparticles from $5.8 \mathrm{~nm}$ (356) up to $8.8 \mathrm{~nm}$ (483) hydrodynamic diameter (Figure S14 and Table S3). These polyplexes have very comparable in vitro gene silencing efficiency (Figure S15) and also in vivo distribution kinetics (Figure S16). In vivo stability of nanoparticles could be demonstrated detecting siRNA-loaded polyplexes but no free siRNA in the urine of intravenously treated mice (Figure S17). Although no significant amounts of labeled siRNA were found in the tumor tissue, still some aster formation was observed using siEG5-Inf7 but not control siCtrl-Inf7 polyplexes (Figure $6 \mathrm{c}$ ), demonstrating a moderate gene silencing effect. Efficacy was clearly lower than in the case of intratumoral administration, with 3-fold lower frequency of aster formations (by histological count) after i.v. injection as compared to i.t. injection. The moderate performance upon systemic application is not surprising considering the rapid renal clearance.

\section{CONCLUSION}

We developed a highly functionalized and on molecular level defined carrier system for siRNA delivery in vitro and in vivo. The design of a chemically precise cationic (oligoethanamino)amide backbone carrying PEG for surface shielding attached to folic acid as targeting ligand and cysteines for bioreversible internal polyplex stabilization, combined with an endosomolytic influenza peptide-siRNA conjugate, results in a specific and efficient delivery system. The synthetic concept based on solid phase supported peptide chemistry allows full control over the structural design of the cationic carrier, overcoming many problems faced by macromolecular carrier synthesis. The monodisperse structures were thoroughly analyzed, and very stable siRNA polyplex formation could be established. The requirement of every single substructure could be demonstrated in individual experiments by comparison with the same system lacking the according substructure. The requirement of each individual function could be demonstrated by silencing a reporter gene or an endogenous target, EG5/KSP, in tumors both in vitro and in vivo. In addition, receptor target specificity could be demonstrated by nearinfrared fluorescence imaging experiments. The nanosized appearance of these functionally active particles (controlled by polymer design; in the current study from 5.8 up to $8.8 \mathrm{~nm}$ hydrodynamic diameter) in combination with the high stability and complete surface charge shielding resulted in high tolerability in vivo and the absence of unspecific accumulation in nontargeted tissue such as liver, lung, or spleen.

The presented study demonstrates that functionally sophisticated but still molecularly monodisperse delivery systems can be generated by convenient solid phase syntheses, which allow the determination of clear structure-activity relationships and simplifies reproducible and scalable manufacturing. Based on the current proof of concept study for this kind of delivery system, the overall strategy enables the generation of a variety of nucleic acid carriers with other targeting ligands (including peptides, our unpublished results), altered degree and type of shielding, different 
polymeric backbone, or endosomal escape domains, leading always to a defined, monodisperse structure with specific properties. Therefore, the devised strategy widens the scope of vector design for the development of efficient siRNA, pDNA, and other oligonucleotide carrier systems.

\section{METHODS}

Synthesis of Folic Acid Targeted Polycations and Its Controls. Oligomers (sequences are listed in Table S5) were synthesized by standard Fmoc-based solid phase supported peptide synthesis using novel building blocks. ${ }^{28}$ As solid support 2-chlorotrityl chloride resin was used.

To load the first amino acid, the resin was swollen in dichloromethane (DCM) for $30 \mathrm{~min}$ and $\mathrm{N}, \mathrm{N}$-dimethylformamide (DMF) for $10 \mathrm{~min}$. Then 0.5 equiv of Fmoc-Cys(Trt)-OH and 10 equiv of diisopropylethylamine (DIPEA) were added in dry DCM. After $60 \mathrm{~min}$ incubation methanol $(0.8 \mathrm{~mL} / \mathrm{g}$ resin) was added. The mixture was incubated for an additional $30 \mathrm{~min}$. The resin was washed five times with DMF and five times with DCM. To quantify the loading, the resin was dried in vacuo. After cleaving the Fmoc protecting group it was quantified by absorption measurement at $301 \mathrm{~nm}$. For carrier chain elongation building blocks (4 equiv) were activated with $\mathrm{PyBOP} / \mathrm{HOBt}$ (4 equiv) and DIPEA (8 equiv) in DCM/DMF, 1:1 (v/v), and the resin was incubated until the Kaiser test indicated completion of reaction. Removal of the Fmoc protecting groups was performed by washing the resin four times for $10 \mathrm{~min}$ with $20 \%$ piperidine in DMF.

The functional construct (FolA-PEG ${ }_{24}-\mathrm{K}\left(\mathrm{Stp}_{4}-\mathrm{C}\right)_{2}$ ) was synthesized starting with a resin-bound $\mathrm{Cys}(\mathrm{Trt})$. First the polyamido backbone was generated by sequential coupling of 4 Stp building blocks, a Dde-Lys(Fmoc)-OH as branching unit, 4 additional Stp building blocks, and finally Boc-Cys(Trt)-OH. The Dde protecting group was removed by washing the resin with $2 \%$ hydrazine in DMF until completion of cleavage was confirmed by lack of absorption at $290 \mathrm{~nm}$. At the free amine the synthesis was continued, adding first a defined Fmoc- $\mathrm{PEG}_{24}-\mathrm{OH}$ (QuantaBiodesign, Powell, $\mathrm{OH}$, USA) building block followed by Fmoc-Glu-OtBu and finally $N^{10}$-(trifluoroacetyl)pteroic acid. The tfa-protecting group was removed using $1 \mathrm{M}$ ammonium hydroxide/DMF, 1:1 (v/v). The resin was dried in vacuo. As cleavage cocktail TFA/TIS/water (95:2.5:2.5) at an incubation time of $1 \mathrm{~h}$ was used. After evaporation of solvents, the peptide was precipitated twice in ice cold methyl tertiary butyl ether (MTBE)/n-hexane, 1:1 (v/v), dissolved in $0.1 \%$ TFA in water, and lyophilized.

The serine control (FolA-PEG $24-\mathrm{K}\left(\mathrm{Stp}_{4}-\mathrm{S}\right)_{2}$ ) was synthesized according to the described procedure using resin bound Ser$(\mathrm{tBu})$ and adding a Fmoc-Ser(tBu)-OH at the end of the sequence followed by bocylation of the $\mathrm{N}$-terminus.

The untargeted control was synthesized persuing the same conditions, starting with resin-bound Fmoc-Ala-OH and FmocLys(Fmoc)-OH as branching unit.

The identity of the structure was confirmed by MALDI-MS, and the purity was established by analytical RP-HPLC.

Synthesis of Endosomolytic-Active siRNA-Peptide Conjugate. The used siRNA was modified at its $5^{\prime}$-end with a $\mathrm{C}_{6}$-ss- $\mathrm{C}_{6}$ spacer. The siRNA was incubated with tris(2-chlorethyl)phosphate (10 equiv) for $30 \mathrm{~min}$ at $25^{\circ} \mathrm{C}$, resulting in siRNA with a free thiol group. Purification was performed on a $1 \mathrm{~mL}$ ResourceQcolumn connected to an Äkta basic system. The sample was loaded onto the column using a 20 mM HEPES buffer ( $\mathrm{pH} 6.5$ ) containing $50 \mathrm{mM}$ sodium chloride. After washing the column with the same buffer containing $200 \mathrm{mM}$ sodium chloride the product was eluted running a sodium chloride gradient of $10 \mathrm{mM} / \mathrm{min}$ at a flow of $1 \mathrm{~mL} / \mathrm{min}$. Fractions containing siRNA were pooled. For activation of the thiol, the siRNA was incubated with 5,5'-dithiobis(2-nitrobenzoic acid) (10 equiv) for $1 \mathrm{~h}$ at RT. The resulting product was purified employing the same conditions as described above. The resulting activated siRNA was incubated with 1.5 equiv of Inf7-peptide (GLFE AIEG FIEN GWEG MIDG WYGC, Biosyntan, Berlin, Germany). The resulting siRNA-peptide conjugate was purified using the same conditions as described above. Fractions of $0.5 \mathrm{~mL}$ were collected and analyzed in a $2.5 \%$ agarose gel (100 V for $100 \mathrm{~min}$ ). Fractions containing gel-retarded siRNA compared to a unconjugated input siRNA were pooled. Identity was checked by MALDI-TOF-MS analysis.

MALDI-TOF-MS Analyses. Peptidic Carrier Molecules. Analysis of peptidic carrier molecules was performed at Roche Kulmbach. Samples were dissolved in $\mathrm{H}_{2} \mathrm{O}$ containing $0.1 \%$ TFA and adjusted to a final concentration of approximately $0.1 \mathrm{mg} / \mathrm{mL}$. For MALDI-TOF-MS stainless steel targets were used. Samples $(1 \mu \mathrm{L})$ were spotted onto a $1 \mu \mathrm{L}$ matrix droplet consisting of a 2,5-dihydroxybenzoic acid solution $(10 \mathrm{mg} / \mathrm{mL})$ in $50 \%$ acetonitrile with $0.1 \%$ TFA. Samples were air-dried and analyzed employing an Autoflex II mass spectrometer (Bruker Daltonics, Bremen, Germany) in reflector mode. Desorption of the samples was achieved by a nitrogen laser $(337 \mathrm{~nm})$, and probes were accelerated with $19 \mathrm{kV}$. For one sample spectrum, 100-200 individual spectra of the respective probes were averaged. A peptide standard served as an external calibration mixture.

Nucleic Acid Constructs. Samples were used as collected after ion exchange purification. To minimize additional salt peaks, $5 \mu \mathrm{L}$ of the samples was desalted by drop dialysis using an ultrafiltration membrane (Millipore) on a Petri dish filled with $\mathrm{H}_{2} \mathrm{O}$ for $2 \mathrm{~h}$. Then $0.5 \mu \mathrm{L}$ of this solution was spotted on a $0.5 \mu \mathrm{L}$ matrix droplet consisting of a saturated solution of 3-hydroxypicolinic acid in $50 \%$ acetonitrile. Samples were analyzed using an Autoflex II mass spectrometer (Bruker Daltonics). For one sample spectrum, 50-100 spectra of respective probes were averaged.

Analytical RP-HPLC. Determination of sample purity was performed using a Waters HPLC system consisting of a P-900 gradient pump system and a 996 photodiode array detector. All peptidic structures were analyzed using a Sunfire C18 column $(5 \mu \mathrm{m}, 4.6 \times 150 \mathrm{~mm})$, using a water/acetonitrile gradient (95:5 to $0: 100$ in $20 \mathrm{~min}$ ) containing $0.1 \%$ TFA. Analysis was performed using a detection wavelength of $214 \mathrm{~nm}$.

Erythrocyte Leakage Assay. Murine erythrocytes were isolated from fresh, citrate-buffered blood and washed with phosphatebuffered saline (PBS) until the supernatant remained clear. The erythrocytes were diluted in PBS $\left(\mathrm{pH} 5.5,6.5\right.$, or 7.4) to $10^{7}$ erythrocytes $/ \mathrm{mL}$. The siRNA-peptide hybrid or free peptide was diluted in $75 \mu \mathrm{L}$ of PBS (pH 5.5, 6.5, or 7.4) to a concentration of $10 \mu \mathrm{M}$. Using a V-bottom 96-well plate (NUNC, Denmark), $75 \mu \mathrm{L}$ of erythrocyte suspension was mixed with $75 \mu \mathrm{L}$ of peptide solution. For $100 \%$ lysis, cells were mixed with $75 \mu \mathrm{L}$ of $1 \%$ Triton X-100. After incubation for $1 \mathrm{~h}$ at $37{ }^{\circ} \mathrm{C}$ under constant shaking the erythrocytes were centrifuged. A $80 \mu \mathrm{L}$ portion of the supernatant was analyzed for hemoglobin release at $405 \mathrm{~nm}$ using a microplate plate reader (Spectrafluor Plus, Tecan Austria GmbH, Grödig, Austria). Measurement data are presented as mean of triplicates.

Cell Culture. Human cervix carcinoma cells were used either as wild-type (KB cells) or stably transfected with the eGFPluciferase gene (KB/eGFPLuc cells). Cells were grown in folatefree RPMI 1640 medium (Invitrogen, Germany), supplemented with $10 \%$ fetal calf serum (FCS), $4 \mathrm{mM}$ stable glutamine, $100 \mathrm{U} / \mathrm{mL}$ penicillin, and $100 \mu \mathrm{g} / \mathrm{mL}$ streptomycin.

As a control murine neuroblastoma cells either wild-type (Neuro2A) or stably transfected with the eGFP-luciferase gene (Neuro2A/eGFPLuc) were grown in Dulbecco's modified Eagle's medium, supplemented with $10 \%$ FCS, 4 mM stable glutamine, $100 \mathrm{U} / \mathrm{mL}$ penicillin, and $100 \mu \mathrm{g} / \mathrm{mL}$ streptomycin.

Polyplex Formation. A $270 \mathrm{ng}$ amount of siRNA and the calculated amount of polycation at different N/P ratios (protonatable nitrogens of polycation/phosphate groups of nucleic acid) were diluted in separate Eppendorf tubes each containing $10 \mu \mathrm{L}$ of $20 \mathrm{mM}$ HEPES-buffered $5 \%$ glucose $\mathrm{pH} 7.4$ (HBG), 
followed by addition of polycation solution to the siRNA solution and rapid mixing by pipetting up and down (minimum five times) and incubation for 45-120 min at RT under air, in order to allow formation of polyplexes with internal disulfide links due to air oxidation of the oligomer thiols during the polyplex formation time. ${ }^{27,29}$ Disulfide formation was quantified with Ellman's assay as described therein. ${ }^{27,29}$ Reduction of free thiol groups was used as an indicator of disulfide formation. See for example Figure S19 in the Supporting Information.

In Vitro Reporter Gene Silencing. In vitro gene silencing experiments were performed with stably transfected KB/eGFPLuc or Neuro2A/eGFPLuc cells. Used siRNAs were either the unmodified siRNAs siGFP (sense: 5'-AuAucAuGGccGAcAAGcAdTsdT-3'; antisense: $5^{\prime}$-UGCUUGUCGGCCAUGAuAUdTsdT-3') for silencing the eGFPLuc fusion protein and its control sequence siCtrl (sense: 5'-AuGuAuuGGccuGuAuuAGdTsdT-3'; antisense: 5'CuAAuAcAGGCcAAuAcAUdTsdT-3') or the peptide modified sequences siGFP-Inf7 (sense: Inf7-ss- $C_{6}-5^{\prime}$-AuAucAuGGccGAcAAGcAdTsdT-3'; antisense: 5'-UGCUUGUCGGCCAUGAuAUdTsdT-3') and its control sequence siCtrl-Inf7 (sense: Inf7-ss- $\mathrm{C}_{6}-5^{\prime}-\mathrm{Au}^{-}$ GuAuuGGccuGuAuuAGdTsdT-3'; antisense: $5^{\prime}$-CuAAuAcAGGCcAAuAcAUdTsdT-3') (small letters: 2'-methoxy-RNA; s: phosphorothioate). Silencing experiments were performed in 96well plates with 5000 cells per well in triplicates with a final siRNA concentration of $200 \mathrm{nM}$ unless otherwise stated. Cells were seeded $24 \mathrm{~h}$ prior to transfection. On the day of transfection, medium was replaced by $80 \mu \mathrm{L}$ of fresh folate-free RPMI 1640 medium containing 10\% FCS. Polyplexes were formed for $45 \mathrm{~min}$ at different N/P ratios in $20 \mu \mathrm{L}$ of HBG added to each well and incubated at $37{ }^{\circ} \mathrm{C}$ for $48 \mathrm{~h}$. For targeting experiments polyplexes were removed by medium exchange after $30 \mathrm{~min}$. In competition experiments, cells were incubated with free folic acid on ice $30 \mathrm{~min}$ prior to the transfection experiment. At $48 \mathrm{~h}$ post-transfection medium was removed. The cells were treated with $100 \mu \mathrm{L}$ of cell lysis buffer ( $25 \mathrm{mM}$ Tris, pH 7.8, 2 mM EDTA, 2 mM DT, $10 \%$ glycerol, $1 \%$ Triton X-100). Luciferase activity in the lysate $(35 \mu \mathrm{L})$ was measured using a luciferase assay kit (100 $\mu \mathrm{L}$ luciferase assay buffer, Promega, Mannheim, Germany) on a luminometer for $10 \mathrm{~s}$ (Lumat LB9507 instrument, Berthold, Bad Wildbad, Germany). The relative light units were related to buffer-treated control cells.

Fluorescence Microscopy of Aster Formation in Vitro. KB cells $\left(1 \times 10^{4}\right)$ were seeded in $200 \mu \mathrm{L}$ of folate-free RPMI medium supplemented with $10 \%$ FCS using eight-well Labtek chamberslides. Twenty-four hours after seeding medium was replaced by $180 \mu \mathrm{L}$ of fresh medium, siRNA polyplexes were added (50 $\mu \mathrm{L}$ formed in HBG). Experiments were performed using $1 \mu \mathrm{g} /$ well EG5siRNA (sense: 5'-ucGAGAAucuAAAcuAAcudTsdT-3'; antisense: 5'-AGUuAGUUuAGAUUCUCGAdTsdT-3', $1 \mu \mathrm{g} /$ well siCtrl or buffer (HBG). Medium was replaced by fresh medium $30 \mathrm{~min}$ after transfection. After $24 \mathrm{~h}$ transfection medium was removed and cells were washed with $200 \mu \mathrm{L}$ of PBS and fixed with paraformaldehyde (4\%). Nuclei were stained with DAPI, and results were documented using a Zeiss Axiovert 200 (fluorescence microscope, Carl Zeiss AG, Germany) and a Zeiss LSM510 Meta laser scanning microscope.

Flow Cytometric Measurement of Polyplex Uptake. Cells were seeded into 24-well plates at a density of $5 \times 10^{4}$ cells/well. After $24 \mathrm{~h}$, culture medium was replaced with $400 \mu \mathrm{L}$ of fresh growth medium containing 10\% FCS. Transfection complexes for siRNA delivery (Cy5-labeled siRNA-Inf7) at an N/P ratio of $16(100 \mu \mathrm{L}$ in HBG) were added to each well and incubated at $37{ }^{\circ} \mathrm{C}$ for 30 min (final siRNA concentration: $200 \mathrm{nM}$ ). All experiments were performed in duplicates. Subsequently, cells were washed twice with PBS. Cells were detached with trypsin/EDTA and taken up in PBS with 10\% FCS, and flow cytometry was performed using a Cyan ADP flow cytometer (Dako, Hamburg, Germany). Cellular uptake was assayed by excitation of Cy5 at $635 \mathrm{~nm}$ and detection of emission at $665 \mathrm{~nm}$. To discriminate between viable and dead cells, cells were appropriately gated by forward/sideward scatter and pulse width and counterstained with DAPI, and $1 \times 10^{4}$ gated events per sample were collected. Data were recorded by Summit software (Summit, Jamesville, NY, USA) and evaluated by FlowJo software.
Measurement of Particle Size via Fluorescence Correlation Spectroscopy. The particle size of polyplexes was measured by fluorescence correlation spectroscopy using an Axiovert 200 microscope with a ConfoCor2 unit (Carl Zeiss, Jena, Germany). A HeNe laser (633 nm, average power of $50 \mu \mathrm{W}$ at the sample) was used for excitation. The objective was a $40 \times(\mathrm{NA}=1.2)$ water immersion apochromat (Carl Zeiss, Jena, Germany). Particles were formed in a volume of $10 \mu \mathrm{L}$ of HBG with a final concentration of $14.8 \mu \mathrm{M}$ siRNA-Inf7, including $50 \mathrm{nM}$ Cy5-labeled siRNA-Inf7 at indicated N/P ratios. For size measurements using labeled cation, oligomer $\mathbf{5 8 3}$ was used during polyplex formation. After polyplex formation the particles were filled up with $200 \mu \mathrm{L}$ of HBG and transferred to eight-well LabTek I chamber slides (NUNC, Wiesbaden, Germany) for measurement. Three experimental replicates were measured.

Measurement of Zeta Potential. Polyplexes, containing $10 \mu \mathrm{g}$ siRNA, were prepared in $370 \mu \mathrm{L}$ of HBG and filled up with HEPES ( $20 \mathrm{mM}, \mathrm{pH} 7.4$ ) to $1 \mathrm{~mL}$ before measurement. The samples were measured in triplicate using a Zetasizer Nano ZS (Malvern Instruments, Worcestershire, U.K.)

siRNA Binding Assay. A 2.5\% agarose gel containing GelRed was prepared. Polyplexes containing $500 \mathrm{ng}$ of siRNA and cationic oligoaminoamide carriers in different $\mathrm{N} / \mathrm{P}$ ratios were prepared and mixed with loading buffer ( $6 \mathrm{~mL}$ of glycerine, $1.2 \mathrm{~mL}$ of $0.5 \mathrm{M}$ EDTA, $2.8 \mathrm{~mL}$ of $\mathrm{H}_{2} \mathrm{O}, 0.02 \mathrm{~g}$ of xylene cyanol). Electrophoresis was performed at $80 \mathrm{~V}$ for $40 \mathrm{~min}$.

In Vivo Experiments. Female Rj:NMRI-nu (nu/nu) (Janvier, Le Genest-St-Isle, France) mice were housed in isolated ventilated cages under specific pathogen-free conditions with a $12 \mathrm{~h}$ day/ night cycle and food and water ad libitum. Human cervix carcinoma cells (KB wild-type) were cultured as described above. About $5 \times 10^{6}$ cells were injected subcutaneously into the nape of nude mice at an age of 6 weeks. Polyplexes containing $50 \mu \mathrm{g}$ of siRNA (N/P 16) or pure siRNA solved in $50 \mu \mathrm{L}$ (intratumoral injection) or $250 \mu \mathrm{L}$ (intravenous injection) of HBG were injected either into the tumor or into the tail vein of tumorbearing mice. All animal experiments were performed according to the guidelines of the German law for protection of animal life and approved by the local ethics committee.

In Vivo Near-Infrared Fluorescence Imaging. Near-infrared fluorescence imaging was performed using the IVIS Lumina system with Living Image software 3.2 (Caliper Life Sciences, Hopkinton, MA, USA). Mice were anesthetized with $3 \%$ isoflurane in oxygen. For the distribution analysis of the polyplexes FolA$\mathrm{PEG}_{24}-\mathrm{K}\left(\mathrm{Stp}_{4}-\mathrm{C}\right)_{2}$, FolA-PEG $_{48}-\mathrm{K}\left(\mathrm{Stp}_{4}-\mathrm{C}\right)_{2}$, or FolA-PEG $72-\mathrm{K}\left(\mathrm{Stp}_{4}-\mathrm{C}\right)_{2}$ each containing Cy7-labeled siAHA1 (sense: $5^{\prime}-(\mathrm{Cy} 7)\left(\mathrm{NHC}_{6}\right)^{-}$ GGAuGAAGuGGAGAuuAGudTsdT-3'; antisense: 5'-ACuAAUCUCcACUUcAUCCdTsdT-3') were injected intravenously. Fluorescence measurement by a CCD camera was started immediately after injection and repeated after $0.25,1,4$, and $24 \mathrm{~h}$. To demonstrate the functionality of receptor targeting in vivo FolA$\mathrm{PEG}_{24}-\mathrm{K}\left(\mathrm{Stp}_{4}-\mathrm{C}\right)_{2}$ containing siAHA1-Cy7, A-PEG $24-\mathrm{K}\left(\mathrm{Stp}_{4}-\mathrm{C}\right)_{2}$ containing siAHA1-Cy7, or pure siAHA1-Cy7 was injected intratumorally. Fluorescence signal was measured after 0, 4, 24, $48,72,96$, and 120 h. Data interpretation was done with equalized color bar scales for each trial.

Urine Sample Collection. For the analysis of the polyplex stability by gel electrophoresis urine was collected by bladder puncture. Mice treated intravenously with FolA-PEG ${ }_{24}-\mathrm{K}\left(\mathrm{Stp}_{4^{-}}\right.$ C) 2 containing Cy7-labeled siAHA1, FolA-PEG $72-K\left(\mathrm{Stp}_{4}-\mathrm{C}\right)_{2}$ containing Cy7-labeled siAHA1, or pure siEG5-Inf7 were anesthetized $4 \mathrm{~h}$ after application and blindly punctured in the dorsal position with an insulin syringe.

EG5 Knockdown As Evaluation of Gene Silencing in Vivo. In the intratumoral EG5 knockdown experiment, mice were injected with FolA-PEG $24-\mathrm{K}\left(\mathrm{Stp}_{4}-\mathrm{C}\right)_{2}$ combined with siEG5-Inf7 or siCtrlInf7 intratumorally also 48 and $24 \mathrm{~h}$ before euthanasia. Tumors were harvested, fixed in formalin, and embedded into paraffin. Then the tumors were cut into $4.5 \mu \mathrm{m}$ slices. After hematoxylin and eosin staining, results were documented using an Olympus BX41 microscope (Olympus, Germany). In the intravenous EG5 knockdown experiments, mice were treated intravenously with FolA-PEG ${ }_{24}-\mathrm{K}\left(\mathrm{Stp}_{4}-\mathrm{C}\right)_{2}$ containing siEG5-Inf7, FolA-PEG ${ }_{24^{-}}$ $\mathrm{K}\left(\mathrm{Stp}_{4}-\mathrm{C}\right)_{2}$ containing siCtrl-Inf7, or $\mathrm{A}-\mathrm{PEG}_{24}-\mathrm{K}\left(\mathrm{Stp}_{4}-\mathrm{C}\right)_{2}$ containing siEG5-Inf7 48 and $24 \mathrm{~h}$ before euthanasia. Tumors were 
harvested and embedded into Tissue-Tek. Then tumors were cut into $5 \mu \mathrm{m}$ slices using a cryotom, fixed with paraformaldehyde, and stained with DAPI. Results were documented with a Zeiss Axiovert 200 fluorescence microscope (Carl Zeiss AG, Germany).

Conflict of Interest: The authors declare no competing financial interest.

Acknowledgment. This work was supported by the DFG Cluster "Nanosystems Initiative Munich", a grant from Roche Kulmbach, and the Biotech Cluster m4 T12.

Supporting Information Available: Data on structural analysis, size, and zeta potential, FACS data and microscopic pictures of uptake, toxicity in vitro, distribution in vivo, structure and functionality of structures with longer PEG chains, urine analysis, and aster detection after systemic administration. This material is available free of charge via the Internet at http:// pubs.acs.org.

\section{REFERENCES AND NOTES}

1. Gao, K.; Huang, L. Nonviral Methods for SiRNA Delivery. Mol. Pharm. 2009, 6, 651-658.

2. Wang, J.; Lu, Z.; Wientjes, M. G.; Au, J. L. Delivery of SiRNA Therapeutics: Barriers and Carriers. AAPS J. 2010, 12, 492503.

3. Alexis, F.; Pridgen, E.; Molnar, L. K.; Farokhzad, O. C. Factors Affecting the Clearance and Biodistribution of Polymeric Nanoparticles. Mol. Pharm. 2008, 5, 505-515.

4. Kwok, A.; Hart, S. L. Comparative Structural and Functional Studies of Nanoparticle Formulations for DNA and SiRNA Delivery. Nanomedicine 2011, 7, 210-219.

5. Meade, B. R.; Dowdy, S. F. The Road to Therapeutic RNA Interference (RNAi): Tackling the 800 Pound Sirna Delivery Gorilla. Discovery Med. 2009, 8, 253-256.

6. Xing, J.; Deng, L.; Guo, S.; Dong, A.; Liang, X. J. Polycationic Nanoparticles as Nonviral Vectors Employed for Gene Therapy in Vivo. Mini-Rev. Med. Chem. 2010, 10, 126-137.

7. Wagner, E. Polymers for SiRNA Delivery: Inspired by Viruses to Be Targeted, Dynamic, and Precise. Acc. Chem. Res. 2012, http://dx.doi.org/10.1021/ar2002232.

8. Andaloussi, S. E.; Lehto, T.; Mager, I.; Rosenthal-Aizman, K.; Oprea, I. I.; Simonson, O. E.; Sork, H.; Ezzat, K.; Copolovici, D. M.; Kurrikoff, K.; et al. Design of a Peptide-Based Vector, Pepfect6, for Efficient Delivery of SiRNA in Cell Culture and Systemically in Vivo. Nucleic Acids Res. 2011, 39, 39723987.

9. Matsumoto, S.; Christie, R. J.; Nishiyama, N.; Miyata, K.; Ishii, A.; Oba, M.; Koyama, H.; Yamasaki, Y.; Kataoka, K. Environment-Responsive Block Copolymer Micelles with a Disulfide Cross-Linked Core for Enhanced SiRNA Delivery. Biomacromolecules 2009, 10, 119-127.

10. Rozema, D. B.; Lewis, D. L.; Wakefield, D. H.; Wong, S. C.; Klein, J. J.; Roesch, P. L.; Bertin, S. L.; Reppen, T. W.; Chu, Q.; Blokhin, A. V.; et al. Dynamic Polyconjugates for Targeted in Vivo Delivery of SiRNA to Hepatocytes. Proc. Natl. Acad. Sci. U. S. A. 2007, 104, 12982-12987.

11. Creusat, G.; Thomann, J. S.; Maglott, A.; Pons, B.; Dontenwill, M.; Guerin, E.; Frisch, B.; Zuber, G. PyridylthioureaGrafted Polyethylenimine Offers an Effective Assistance to SiRNA-Mediated Gene Silencing in Vitro and in Vivo. J. Controlled Release 2012, 157, 418-426.

12. Mao, S.; Neu, M.; Germershaus, O.; Merkel, O.; Sitterberg, J.; Bakowsky, U.; Kissel, T. Influence of Polyethylene Glycol Chain Length on the Physicochemical and Biological Properties of Poly(Ethylene Imine)-Graft-Poly(Ethylene Glycol) Block Copolymer/SiRNA Polyplexes. Bioconiugate Chem. 2006, 17, 1209-1218.

13. Malek, A.; Czubayko, F.; Aigner, A. Peg Grafting of Polyethylenimine (PEI) Exerts Different Effects on DNA Transfection and SiRNA-Induced Gene Targeting Efficacy. J. Drua Targeting 2008, 16, 124-139.

14. Taratula, O.; Garbuzenko, O. B.; Kirkpatrick, P.; Pandya, I.; Savla, R.; Pozharov, V. P.; He, H.; Minko, T. Surface-Engineered
Targeted PPI Dendrimer for Efficient Intracellular and Intratumoral SiRNA Delivery. J. Controlled Release 2009, 140, 284293.

15. Walker, G. F.; Fella, C.; Pelisek, J.; Fahrmeir, J.; Boeckle, S.; Ogris, M.; Wagner, E. Toward Synthetic Viruses: Endosomal pH-Triggered Deshielding of Targeted Polyplexes Greatly Enhances Gene Transfer in Vitro and in Vivo. Mol. Ther. 2005, 11, 418-425.

16. Meyer, M.; Philipp, A.; Oskuee, R.; Schmidt, C.; Wagner, E. Breathing Life into Polycations: Functionalization with $\mathrm{pH}-$ Responsive Endosomolytic Peptides and Polyethylene Glycol Enables SiRNA Delivery. J. Am. Chem. Soc. 2008, 130, 3272-3273.

17. Ikeda, Y.; Taira, K. Ligand-Targeted Delivery of Therapeutic SiRNA. Pharm. Res. 2006, 23, 1631-1640.

18. Plank, C.; Oberhauser, B.; Mechtler, K.; Koch, C.; Wagner, E. The Influence of Endosome-Disruptive Peptides on Gene Transfer Using Synthetic Virus-Like Gene Transfer Systems. J. Biol. Chem. 1994, 269, 12918-12924.

19. Wagner, E.; Plank, C.; Zatloukal, K.; Cotten, M.; Birnstiel, M. L. Influenza Virus Hemagglutinin HA-2 N-Terminal Fusogenic Peptides Augment Gene Transfer by TransferrinPolylysine-DNA Complexes: Toward a Synthetic Virus-Like Gene-Transfer Vehicle. Proc. Natl. Acad. Sci. U. S. A. 1992, 89, 7934-7938.

20. Meyer, M.; Dohmen, C.; Philipp, A.; Kiener, D.; Maiwald, G.; Scheu, C.; Ogris, M.; Wagner, E. Synthesis and Biological Evaluation of a Bioresponsive and Endosomolytic SiRNAPolymer Conjugate. Mol. Pharm. 2009, 6, 752-762.

21. Zuber, G.; Zammut-Italiano, L.; Dauty, E.; Behr, J. P. Targeted Gene Delivery to Cancer Cells: Directed Assembly of Nanometric DNA Particles Coated with Folic Acid. Angew. Chem. Int. Ed. 2003, 42, 2666-2669.

22. Erbacher, P.; Remy, J. S.; Behr, J. P. Gene Transfer with Synthetic Virus-Like Particles Via the Integrin-Mediated Endocytosis Pathway. Gene Ther. 1999, 6, 138-145.

23. DeRouchey, J.; Walker, G. F.; Wagner, E.; Radler, J. O. Decorated Rods: A "Bottom-Up" Self-Assembly of Monomolecular DNA Complexes. J. Phys. Chem. B 2006, 110, 4548-4554.

24. DeRouchey, J.; Schmidt, C.; Walker, G. F.; Koch, C.; Plank, C.; Wagner, E.; Radler, J. O. Monomolecular Assembly of SiRNA and Poly(Ethylene Glycol)-Peptide Copolymers. Biomacromolecules 2008, 9, 724-732.

25. Akinc, A.; Goldberg, M.; Qin, J.; Dorkin, J. R.; Gamba-Vitalo, C.; Maier, M.; Jayaprakash, K. N.; Jayaraman, M.; Rajeev, K. G.; Manoharan, M.; et al. Development of Lipidoid-SiRNA Formulations for Systemic Delivery to the Liver. Mol. Ther. 2009, 17, 872-879.

26. Hartmann, L.; Hafele, S.; Peschka-Suss, R.; Antonietti, M.; Borner, H. G. Tailor-Made Poly(Amidoamine)s for Controlled Complexation and Condensation of DNA. Chemistry 2008, 14, 2025-2033.

27. Schaffert, D.; Troiber, C.; Salcher, E. E.; Frohlich, T.; Martin, I.; Badgujar, N.; Dohmen, C.; Edinger, D.; Klager, R.; Maiwald, G.; et al. Solid-Phase Synthesis of Sequence-Defined T-, I-, and U-Shape Polymers for pDNA and SiRNA Delivery. Angew. Chem., Int. Ed. 2011, 50, 8986-8989.

28. Schaffert, D.; Badgujar, N.; Wagner, E. Novel Fmoc-Polyamino Acids for Solid-Phase Synthesis of Defined Polyamidoamines. Org. Lett. 2011, 13, 1586-1589.

29. Fröhlich, T.; Edinger, D.; Klager, R.; Troiber, C.; Salcher, E.; Badgujar, N.; Martin, I.; Schaffert, D.; Cengizeroglu, A.; Hadwiger, P.; et al. Structure-Activity Relationships of SiRNA Carriers Based on Sequence-Defined Oligo (Ethane Amino) Amides. J. Controlled Release 2012, 160, 532-541.

30. Wang, S.; Lee, R. J.; Mathias, C. J.; Green, M. A.; Low, P. S. Synthesis, Purification, and Tumor Cell Uptake of 67GaDeferoxamine--Folate, a Potential Radiopharmaceutical for Tumor Imaging. Bioconjugate Chem. 1996, 7, 56-62.

31. Boeckle, S.; von Gersdorff, K.; van der Piepen, S.; Culmsee, C.; Wagner, E.; Ogris, M. Purification of Polyethylenimine Polyplexes Highlights the Role of Free Polycations in Gene Transfer. J. Gene Med. 2004, 6, 1102-1111. 
32. Plank, C.; Mechtler, K.; Szoka, F. C., Jr.; Wagner, E. Activation of the Complement System by Synthetic DNA Complexes: A Potential Barrier for Intravenous Gene Delivery. Hum. Gene Ther. 1996, 7, 1437-1446.

33. Hamad, I.; Al-Hanbali, O.; Hunter, A. C.; Rutt, K. J.; Andresen, T. L.; Moghimi, S. M. Distinct Polymer Architecture Mediates Switching of Complement Activation Pathways at the Nanosphere-Serum Interface: Implications for Stealth Nanoparticle Engineering. ACS Nano 2010, 4, 6629-6638.

34. Kamen, B. A.; Capdevila, A. Receptor-Mediated Folate Accumulation Is Regulated by the Cellular Folate Content. Proc. Natl. Acad. Sci. U. S. A. 1986, 83, 5983-5987.

35. Xia, W.; Low, P. S. Folate-Targeted Therapies for Cancer. J. Med. Chem. 2010, 53, 6811-6824.

36. Judge, A. D.; Robbins, M.; Tavakoli, I.; Levi, J.; Hu, L.; Fronda, A.; Ambegia, E.; McClintock, K.; MacLachlan, I. Confirming the RNAi-Mediated Mechanism of Action of SiRNA-Based Cancer Therapeutics in Mice. J. Clin. Invest. 2009, 119, 661673. 